\title{
Relaciones artísticas entre la Haggadah de Sarajevo y la cerca exterior del coro de la catedral de Toledo *
}

\author{
M. ${ }^{a}$ Angela Franco Mata **
}

Durante el pontificado del arzobispo don Pedro Tenorio (1376-1399) se termina el trascoro de la catedral de Toledo, en cuyo libro Obra y Fábrica correspondiente al año 1383 se cita la entrega de "otro capitel de los de las capilletas e otro de los boceles mayores..." por Ferrand González. Dichas obras, supone T. Pérez Higuera ', iban destinadas al cerramiento del coro que se ejecutaba por entonces. En la parte exterior de dicha cerca se dispuso una serie de 56 relieves relativos a los dos primeros libros del Pentateuco, el Génesis y el Exodo, en relación directa con la liturgia de la Vigilia Pascual. Se han interpolado varias escenas de carácter legendario, tomadas de diversas narraciones literarias medievales, refierentes a Caín, Abel, Seth, muerte de Adán y el árbol de la cruz.

En un trabajo que publiqué sobre el tema en $1987^{2}$, ya indiqué conexiones entre la cerca exterior del coro toledano y la Haggadah de Sarajevo, la más rica en iluminación de este tipo de manuscritos judíos, de los que se conservan completos o incompletos una veintena ${ }^{3}$. De nuevo sobre el tema, pueden precisarse varios aspectos y abrir nuevos interrogantes.

* Comunicación presentada en el Encuentro Internacional de Historiadores En torno a Sefarad. Toledo, 1991.

** Museo Arqueológico Nacional (Madrid).

1 Pérez Higuera, T., "Ferrand González y los sepulcros del taller toledano (1385-1410)", Boletín del Seminario de Arte y Arqueologia. Universidad de Valladolid, XLIV, 1978, pág. 131.

2 "El Génesis y el Exodo en la cerca exterior del Coro de la Catedral de Toledo", Toletvm. Toledo, n. 21, 1987, págs. 53-160.

3 NaRkiS, B., Hebrew Illuminated Manuscripts in the British Isles. I. The Spanish and Potuguese Manusccripts, Jerusalén-Londres 1982, vol. I, pág. 42. Para las Haggadot vid también METZGER, M., La Haggada enluminée. I. Etude iconographique et stylistique des manuscrits enluminés et décorés de la Haggada, du XIIIe au XVle siècle. Leiden 1973. 
La Haggadáh de Sarajevo procede del reino de Aragón, como se colige del escudo con las barras verticales de la Casa Real de Aragón (fol. 3), que no es indicativo de su pertenencia, sino como homenaje. Hay que advertir que en él estaba incluida Cataluña, de cuya área cercana a Barcelona, o de esta misma ciudad, proviene indudablemente. Werber dice que el encargante o posesor pertenecía a la familia Sanz - ala del escudo en el ángulo inferior derecho- y a la reina Margarita de Aragón -roseta en el ángulo contrario- ${ }^{4}$, 10 cual en docta opinión de F. Menéndez-Pidal ${ }^{5}$, no es cierto en modo alguno. El ala, advierte, es muy frecuente en el área catalano-valenciana, y la familia Sanz precisamente no es la posesora del escudo casi con toda seguridad, pues a su escudo se le concedió un feje de Aragón en lugar de honor. La roseta de la pretendida reina Margarita es totalmente inadmisible. Los diversos autores la vienen datando hacia 1350 - Narkiss ${ }^{6}$ - o ligeramente más tarde - C., Roth ${ }^{7}$, E. Werber ${ }^{8}-$.

Se ha mencionado reiteradamente su influencia italiana, y es cierto, pero es preciso aquilatar conceptos ${ }^{9}$. Ferrer Bassa es el introductor de las formas sienesas, como se ve en los frescos de la capilla de San Miguel del monasterio de Pedralbes, contratados en 1343 y realizados en 1346, presumiblemente con su hijo Arnau Bassa, pues están asociados entre 1345 y $1348{ }^{10}$. La Haggadah de Sarajevo, sin embargo, está más influida por otras obras de dichos pintores, particularmente el retablo de San Marcos -iglesia de Santa María de Manresa - y el libro de Horas de la reina María de Navarra - ca. 1338-1342-, de Ferrer Bassa ${ }^{11}$. También se advierten ecos del arte de Ramón Destorrents ${ }^{12}$. Y he resaltado la influencia estilística en los relieves toledanos que no es en absoluto sorprendente, pues varios arzobispos del siglo XIV tuvieron relaciones directas con el vecino país, sobre todo el infante Don Juan de Aragón y el cardenal don

4 No aparece citado este nombre en el libro de ARCO, R. de, Sepulcros de la Casa Real de Aragón. Madrid 1945.

5 Agradezco dicha información.

6 Manuscritos iluminados hispanohebreos, catálogo de La Vida judía en Sefarad. Toledo. 1991, págs. 189-195.

7 The Sarajevo Haggadah. Belgrado 1975, págs. 8-9.

- The Sarajevo Haggadah. Ljubljana 1988, pág. 20.

- Para la influencia de la pintura gótica italiana en Cataluña vid. MEISS, M., «ltalian Style in Catalonia and a fourteenth century catalan workshopm. The Journal of the Walters Art Gallery, vol. IV, 1941, págs. 45-87, punto de referencia para futuros estudios.

10 Trens, M., Ferrer Bassa i les pintues de Pedralbes. Barcelona 1936.

1 Para la pintura gótica catalana vid. DaLmases, N. de, y José PITARCH, A., Historia de l'art català. Vol. III. L'art g'tic s. XIV-xV. Barcelona 1984, págs. 152-163; GUDIOL, J. y ALCOLEAI BLANCH, S., Pintura gótica catalana. Barcelona 1987, págs. 43-51.

12 Agradezco la opinión de M. Carmen Lacarra. 
Gil Álvarez de Albornoz ${ }^{13}$. No es desdeñable tampoco la relación venida a través de Cataluña.

La Haggadah de Sarajevo responde en la división propuesta por Narkiss al segundo tipo, es decir, el que incluye el Génesis, colocándolo antes del Exodo, libro en rigor obligado, pues la base de la Haggadah es precisamente la conmemoración de la liberación del pueblo judío de Egipto ${ }^{14}$. Ésta junto con la Prato Haggadath son los únicos ejemplos conocidos donde se incluye la creación del mundo, que según Gabrielle Sed-Rajna no aparece en el mundo judío antes del siglo XIV ${ }^{15}$. La inspiración iconográfica del tema proviene evidentemente del mundo cristiano. M. Mentré ve relaciones directas con las Biblias ligadas a Sancho el Fuerte de Navarra, donde el mundo circular y las aguas presentan idéntica estructura ${ }^{16}$. De raíz cristiana es la iluminación a página entera. Narkiss sugiere el modo de iluminar el salterio latino en Inglaterra y Francia, citando como ejemplo el Salterio de San Luis ${ }^{17}$. Sin embargo, más cerca tenemos las propias Cántigas de Alfonso el Sabio, conocidas sobradamente el siglo XIV.

Típicamente judía es la representación de la creación del mundo sin la presencia de la imagen del Creador; ésta se intuye en este caso a través de un haz de rayos ${ }^{18}$, como en el descenso de Moisés del monte con las Tablas de la Ley, si bien aquí la voz sale a través de un cuerno -en el sacrificio de Isaac se ve la Mano Divina. En Toledo, la representación de la Creación es una síntesis de elementos judíos y cristianos; el Creador lleva sobre sus hombros un arco simulando el mundo, pero en la parte inferior las aguas se disimulan por medio de curvas.

Derivación directa de la citada Haggadah es la creación de Adán sin ombligo, dado que no nació de mujer ${ }^{19}$, sino como obra salida de las manos de DiosAlfarero. En la Haggadah de Sarajevo aparecen sin ombligo Adán y Eva, y asímismo en la Biblia de la Casa de Alba. Esta última es obra gótica realizada por miniaiuristas toledanos, según se advierte en el prólogo ${ }^{20}$. En el arte cristiano

${ }^{13}$ He tratado este asunto en la conferencia pronunciada en Aguilar del Campoo el 26 de septiembre de 1991, titulada "Aspectos de la escultura gótica toledana del siglo XIV" (en pren. sa).

14 Hebrew Illuminated Manuscripts..., cit. I, pág. 42.

15 Mentré M., “L'iconographie de la Création dans les bibles liées à Sanche le Fort de Navarre», Midi, 1 dic. 1986, págs. 17-18, notas 12 y 18.

${ }_{16}$ Ibídem, págs. 16-17. Vid. también su comunicación en el presente congreso, titulada "La création de l'universe dans l'art chrétien et dans l'art juif en Espagne du nord avant 1492".

17 Manuscritos iluminados hispanohebreos, cit. pág. 192.

18 Muller, D.H., Die Haggadah von Sarajevo. Viena 1898, fols. 1v, 2, 3v, citado por Narkiss, Manuscritos iluminados hispanohebreos, cit. p. 178

19 Azcárate J.M., (Arte gótico en España. Madrid 1990, pág. 200), dice que se debe a conceptos iconográficos, opinión que no comparto.

${ }_{20}$ Esta última estudiada por NoADStRön, K.O., The Bible of the Casa de Alba. The duke of 
lo normal es que aparezca con ombligo; hasta el propio Bosco pinta así al primer hombre. Es, pues, el mundo judío el que ha influido sobre el cristiano a partir de textos antiguos bíblicos como del Próximo Oriente ${ }^{21}$. Extrañamente no se alude a esta cuestión en la Vita Adae et Evae.

La representación de la muerte de Abel por Caín por un mordisco en la yugular, presente en Toledo, no proviene de la Haggadah de Sarajevo. Su raíz, sin embargo, no es cristiana, sino que está tomada de textos apócrifos judíos - Zohar, Vita Adae et Evae: “Et dixit Eua ad Adam, domine mi dormiens uidi per uisum quod sanguinem filii tui Abel Caym manibus suis perducebat et ore suo deglutit» ${ }^{22}$. Se repetirá un siglo más tarde en la sillería de Belmonte (Cuenca).

Especial énfasis se da en ambas obras a la representación de las plagas de Egipto, lo que sugiere también una relación, máxime considerando que en el arte cristiano no es frecuente. Así lo advierte Réau, que ignora el programa toledano; considera excepcionales el antes mencionado Salterio de San Luis y la Biblia Moralizada, ms. $2554{ }^{23}$. En la Haggadah se figuran las diez plagas, y en el coro de Toledo siete $-1 .^{a}, 2 .^{a}, 4 .^{a}, 5 .^{a}, 7 .^{a}, 8 .^{a}$ y 10. ${ }^{a}$ - Considerando las diferencias de representación entre la pintura y el relieve, se ven, sin embargo, similitudes no casuales: el Faraón sentado ataviado como un monarca medieval coronado - en la Haggadah aparece una vez en pie-. Su actitud es la misma con la diferencia de llevar el cetro en alto - Haggadah-y la espada desenvainada también en alto - Toledo-. En Toledo es más frecuente su disposición en el centro de la escena. La disposición del faraón vestido al modo occidental indica evidentemente inspiración en el mundo cristiano - Golden Haggadah. Pero Toledo se inspira presumiblemente en la citada Haggadah. Del mundo occidental es asimismo el modo de rasgarse las vestiduras los hijos de Jacob ante José

Alba's Castilian Bible. A study of the rabbinical features of the miniatures. Upsala 1967 y Metzger, The "Alba Bible" of Rabbi Moses Arragel, Bulletin of the Institute of Jewish Studies, ill, 1975, págs. 131-155. J. Yarza, La imagen del rey y la imagen del noble en el siglo xv castellano, Realidad e imágenes del poder, España a fines de la Edad Media, pág. 281, Domínguez Rodríguez, A., La ilustración en los manuscritos. Historia ilustrada del libro español. Los manuscritos, dir. por H. Escolar, Madrid, 1993, pág. 347; Sánchez Mariana, M., El libro en la Baja Edad Media. El Reino de Castilla, Historia ilustrada del libro... cit., pág. 214.

${ }_{21}$ Para el presente contexto es especialmente importante el estudio de ERrandonEa, J., Edén y Paraiso. Fondo cultural mesopotámico en el relato biblico de la creación. Madrid 1965 , págs. 21-23. Vid. también el Poema de Gilgamesh, $2{ }^{a}$ ed. Madrid 1983, pág. 116; V.V.A.A., La creación del mundo y del hombre en los textos del Próximo Oriente Antiguo. Estella 1982, págs. 8-40.

Versión de Mozley, cfr. Franco, “El Génesis y el Exodo...”, cit. págs. 77-78.

${ }^{23}$ Iconographie de l'art chrétien. T. II. Iconographie de la bible, I. Ancien Testament. París 1956, págs. $189-190$. 
cuando descubre su copa en el saco de Benjamín, aunque la inspiración de la escena proviene directamente de la Biblia- "Entonces rasgaron ellos sus túnicas..." (Gen., XLIV, 13). Los arbolillos, de copas redondeadas en ésta, se repiten en Toledo, y a veces la rama partida que brota del tronco - se ve muy claramente en el sueño de Jacob-, sistema ya adoptado ocasionalmente en Salisbury -creación de las aves y los peces.

Al estar dedicada la obra toledana al pueblo cristiano, se evita lógicamente el vestir a los personajes al modo judio, pero están presentes los gorros típicos en algunas escenas, como el becerro de oro y en la quema de las Tablas de la Ley.

A través de lo dicho, creo que queda patente la relación entre una y otra obra. No sorprende que en Toledo, donde convivieron las tres religiones, con mayor o menor fortuna, aquélla durante los siglos $x \| 1$ y $x{ }^{21}{ }^{24}$ y ésta especialmente señalada durante la guerra fratricida entre Pedrol y Enrique $\|^{25}$, se ideara un programa iconográfico, que aunque sustancial en la liturgia de la vigilia pascual, estuviera inspirada en el mundo judío. En mi opinión o bien se tomaron diversos pasajes directamente de la citada Haggadah, o de otra similar en Toledo, perdida. Desde luego subyace una intencionalidad de conversión, como se expresa en las Cortes de Alcalá (1348): «porque aun se han a tornar nuestra fe e ser salvos segund se falla por las profeçias" ${ }^{26}$.

Hay, sin embargo, muchos puntos que difieren en ambas obras. Varios de los relieves toledanos están más en consonancia con otro programa iconográfico paralelo anterior un siglo; los relieves de la Chapter House de la catedral de Salisbury (Inglaterra). Aquí están ausentes las plagas de Egipto. Pero las coincidencias con Toledo en varios temas sugieren una posible inspiración. Aunque la moda impone cambios en el tratamiento de los temas, en ocasiones apenas sufren alteraciones, así en la vida de Adán y Eva tras la expulsión del paraiso, Abraham postrado de rodillas ante los tres ángeles, el sacrificio de Isaac, la bendición de Jacob y la posterior de Esaú llorando amargamente, la lucha de Jacob y el ángel. La figura del Padre Eterno tampoco difiere sensiblemente; en Salisbury viste túnica y

24 Tolède XIle-XIIle. Musulmans, chrétiens et juifs: le savoir et la tolérance. Paris 1991; PASTOR DE TOGNERI, Reyna; Del Islam al Cristianismo, en las fronteras de dos formacionessociales: Toledo, siglos IX-XIII, 2. ${ }^{2}$ ed., Barcelona 1985.

25 Valdeón Baruque, J., "La judería toledana en la guerra civil de Pedro I y Enrique Il", Simposio «Toledo Judaico». Toledo 1972, I, págs. 105-131.

26 Ibídem, pág. 108. 
capa y va nimbado; no así en Toledo, donde su atavío es túnica y manto. Los dos programas tienen también inspiración en leyendas medievales -Adán, Caín, Abel y Seth en Toledo y Jacob y José en Inglaterra-.

CORRESPONDENCIA ENTRE LOS PROGRAMAS ICONOGRÁFICOS DE LA CERCA EXTERIOR DE LA CATEDRAL DE TOLEDO, LA HAGGADAH DE SARAJEVO Y LA CHAPTER HOUSE DE LA CATEDRAL DE SALISBURY

\begin{tabular}{|c|c|c|}
\hline TOLEDO & SARAJEVO & SALISBURY \\
\hline \multicolumn{3}{|c|}{ Génesis } \\
\hline \multicolumn{3}{|c|}{ 1. Desde la creación a la muerte de Adán } \\
\hline & $\begin{array}{l}\text { La Voz de Dios represen- } \\
\text { tado como irradiación del } \\
\text { cielo. }\end{array}$ & \\
\hline & $\begin{array}{l}\text { El mundo de lo informe } \\
\text { con el espíritu de Dios. }\end{array}$ & \\
\hline $\begin{array}{l}\text { 1. Jornada: Separación } \\
\text { de la luz y las tinieblas } \\
\text { (Gén. } 1,3-5) \text {. }\end{array}$ & $\begin{array}{l}\text { 1. día: Creación de la luz } \\
\text { (Gén., I,3-5). }\end{array}$ & $\begin{array}{l}\text { 1. a Jornada: Creación de } \\
\text { la luz (Gén., I,3-5). }\end{array}$ \\
\hline \multirow{2}{*}{$\begin{array}{l}\text { 2. Jornada: Creación del } \\
\text { firmamento con la sepa- } \\
\text { ración de las aguas y del } \\
\text { cielo (Gén. I, 6-8). }\end{array}$} & & $\begin{array}{l}\text { 2. Jornada: Creación del } \\
\text { firmamento (Gén., I, 6-8). }\end{array}$ \\
\hline & $\begin{array}{l}\text { 3. Jornada: Creación de } \\
\text { las plantas (Gén., I, } 11 \text {. } \\
\text { 13). }\end{array}$ & $\begin{array}{l}\text { 3. Jornada: Creación de } \\
\text { las plantas (Gén., I, } 11 \text {. } \\
\text { 13). }\end{array}$ \\
\hline \multirow[t]{2}{*}{$\begin{array}{l}\text { 4. Jornada: Creación del } \\
\text { sol y la luna (Gén. I, 14- } \\
\text { 19). }\end{array}$} & $\begin{array}{l}\text { 4. }{ }^{2} \text { Jornada: Creación del } \\
\text { sol y la luna. (Gén. I, 14- } \\
\text { 19). }\end{array}$ & $\begin{array}{l}\text { 4. Jornada: Creación del } \\
\text { sol y la luna. (Gén., I, 14- } \\
\text { 19). }\end{array}$ \\
\hline & $\begin{array}{l}\text { Creación de los peces y } \\
\text { aves (Gén. I, 21). }\end{array}$ & $\begin{array}{l}\text { Creación de los peces y } \\
\text { aves (Gén. I, 21). }\end{array}$ \\
\hline $\begin{array}{l}\text { 5. Jornada: Creación de } \\
\text { los animales (Gén. I, 20- } \\
\text { 23). }\end{array}$ & $\begin{array}{l}\text { 5. Jornada: Creación de } \\
\text { los animales (Gén. I, 20- } \\
\text { 23). }\end{array}$ & $\begin{array}{l}\text { 5. Jornada: Creación de } \\
\text { los animales (Gén. I, 20- } \\
\text { 23). }\end{array}$ \\
\hline $\begin{array}{l}\text { Creación de los ángeles. } \\
\text { (Varios textos en la Bi- } \\
\text { blia). }\end{array}$ & & \\
\hline
\end{tabular}


Relaciones artísticas entre la Haggadah de Sarajevo y la cerca exterior del coro...

(Continuación)

\begin{tabular}{|c|c|c|}
\hline TOLEDO & SARAJEVO & SALISBURY \\
\hline \multicolumn{3}{|l|}{$\begin{array}{l}\text { Caída de los ángeles ma- } \\
\text { los. }\end{array}$} \\
\hline & $\begin{array}{l}\text { El Sabbat personificado } \\
\text { en la figura de un hom- } \\
\text { bre. }\end{array}$ & \\
\hline \multicolumn{3}{|l|}{$\begin{array}{l}\text { 6. Jornada: Creación } \\
\text { del hombre (Gén., I, 26- } \\
27 \text { ). }\end{array}$} \\
\hline & $\begin{array}{l}\text { Creación de Eva (Gén., I, } \\
27 \text { ) }\end{array}$ & $\begin{array}{l}\text { Creación de Eva (Gén., I, } \\
27 \text { ) }\end{array}$ \\
\hline \multirow{2}{*}{$\begin{array}{l}\text { Dios con Adán y Eva des- } \\
\text { nudos, a los que muestra } \\
\text { el árbol (Gén., I, 27; } 11 \text { - } \\
25 \text { ). }\end{array}$} & & $\begin{array}{l}\text { Dios muestra el árbol a } \\
\text { Adán y Eva (Gén., I, 27; } \\
\text { 11-25). }\end{array}$ \\
\hline & $\begin{array}{l}\text { La serpiente incita a Eva } \\
\text { a comer del fruto prohi- } \\
\text { bido (Gén., III, 1-6). }\end{array}$ & $\begin{array}{l}\text { Adán y Eva comen del ár- } \\
\text { bol incitados por la ser- } \\
\text { piente (Gén., III, 1-6). }\end{array}$ \\
\hline $\begin{array}{l}\text { Dios con Adán y Eva tras } \\
\text { el pecado; éstos han cu- } \\
\text { bierto su desnudez con } \\
\text { hojas de higuera (Gén., } \\
\text { III, } 7-19 \text { ). }\end{array}$ & $\begin{array}{l}\text { Adán y Eva cubren su } \\
\text { desnudez volviendo la } \\
\text { vista hacia Dios, cuyo es- } \\
\text { píritu les es comunicado } \\
\text { a través del cielo (Gén., } \\
\text { III, } 7-19 \text { ). }\end{array}$ & $\begin{array}{l}\text { Dios recrimina a Adán y } \\
\text { Eva tras el pecado (Gén., } \\
\text { III, } 7-19 \text { ). }\end{array}$ \\
\hline $\begin{array}{l}\text { Adán y Eva son expul- } \\
\text { sados del paraíso (Gén., } \\
\text { III, 22-24). }\end{array}$ & & $\begin{array}{l}\text { Adán y Eva son expul- } \\
\text { sados del paraíso (Gén, } \\
\text { III, 22-24). }\end{array}$ \\
\hline \multirow[t]{2}{*}{$\begin{array}{l}\text { Adán y Eva sometidos al } \\
\text { trabajo (Gén., III, 23). }\end{array}$} & $\begin{array}{l}\text { Adán y Eva sometidos al } \\
\text { trabajo; Adán cava, Eva } \\
\text { hila y la serpiente repta. }\end{array}$ & $\begin{array}{l}\text { Adán y Eva sometidos al } \\
\text { trabajo; Adán cava y Eva } \\
\text { amamanta a su hijo. }\end{array}$ \\
\hline & $\begin{array}{l}\text { Caín y Abel: ofrenda de } \\
\text { los sacrificios (Gén., IV, } \\
3-4 \text { ). }\end{array}$ & $\begin{array}{l}\text { Caín y Abel: ofrenda de } \\
\text { los sacrificios (Gén., IV, } \\
3-4 \text { ). }\end{array}$ \\
\hline $\begin{array}{l}\text { Caín mata a Abel (Gén., } \\
\text { IV, } 8 \text { ). }\end{array}$ & $\begin{array}{l}\text { Caín mata a Abel (Gén., } \\
\text { IV, 8). }\end{array}$ & $\begin{array}{l}\text { Caín mata a Abel (Gén., } \\
\text { IV, 8). }\end{array}$ \\
\hline $\begin{array}{l}\text { Caín intenta cubrir el ca- } \\
\text { dáver de Abel (Gén., IV, } \\
\text { 10-11). }\end{array}$ & & \\
\hline
\end{tabular}


(Continuación)

\begin{tabular}{|c|c|c|}
\hline TOLEDO & SARAJEVO & SALISBURY \\
\hline $\begin{array}{l}\text { Dios sentencia a Caín } \\
\text { (Gén., IV, 9-16). }\end{array}$ & & $\begin{array}{l}\text { Dios sentencia a Caín } \\
\text { (Gén., IV, 9-16). }\end{array}$ \\
\hline $\begin{array}{l}\text { Lamec mata a Caín } \\
\text { (Gén., IV, 23-24). }\end{array}$ & & \\
\hline Súplica de Adán. & & \\
\hline $\begin{array}{l}\text { Adán manda a Set al pa- } \\
\text { ríso a buscar el óleo del } \\
\text { árbol. }\end{array}$ & & \\
\hline $\begin{array}{l}\text { Set es recibido a las } \\
\text { puertas del paraiso }\end{array}$ & & \\
\hline Sepultura de Adán. & & \\
\hline $\begin{array}{l}\text { El árbol que brota del se- } \\
\text { pulcro de Adán. }\end{array}$ & & \\
\hline \multicolumn{3}{|c|}{ 11. Noé y el diluvio } \\
\hline $\begin{array}{l}\text { Noé construye el arca } \\
\text { (Gén., VI, 9-16). }\end{array}$ & $\begin{array}{l}\text { Noé construye el arca } \\
\text { (Gén., VI, 9-16). }\end{array}$ & $\begin{array}{l}\text { Dios manda a Noé cons- } \\
\text { truir el arca (Gén., VI, 9- } \\
\text { 16) }\end{array}$ \\
\hline \multirow[t]{2}{*}{$\begin{array}{l}\text { El arca flota sobre las } \\
\text { aguas (Gén., VIII, 6-12). }\end{array}$} & $\begin{array}{l}\text { El arca flota sobre las } \\
\text { aguas (Gén., VIII, 6-12) y } \\
\text { la paloma con la rama de } \\
\text { olivo en el pico (Gén., } \\
\text { VIII, 11). }\end{array}$ & $\begin{array}{l}\text { Noé entra en el arca y re- } \\
\text { cibe a la paloma (Gén., } \\
\text { VIII, 6-12). }\end{array}$ \\
\hline & $\begin{array}{l}\text { Noé sale del arca con su } \\
\text { familia y ofrece un cor- } \\
\text { dero en sacrificio (Gén., } \\
\text { VIII, 15-20). }\end{array}$ & \\
\hline \multicolumn{3}{|c|}{ II. Desde el diluvio hasta Abraham. Historia de Abraham } \\
\hline & & $\begin{array}{l}\text { Noé poda la viña (Gén., } \\
\text { IX, 20). }\end{array}$ \\
\hline \multirow{2}{*}{$\begin{array}{l}\text { La embriaguez de Noé. } \\
\text { Cam cubre el cuerpo de } \\
\text { su padre ante sus her- } \\
\text { manos (Gén., IX, 18-27). }\end{array}$} & $\begin{array}{l}\text { Cam revela la desnudez } \\
\text { de su padre a Sem y Ja- } \\
\text { fet (Gén., IX, 22). }\end{array}$ & $\begin{array}{l}\text { La embriaguez de Noé } \\
\text { (Gén. IX, 20). }\end{array}$ \\
\hline & $\begin{array}{l}\text { Construcción de la Torre } \\
\text { de Babel (Gén., XI, 1-9). }\end{array}$ & $\begin{array}{l}\text { Construcción de la torre } \\
\text { de Babel (Gén., XI, 1-9). }\end{array}$ \\
\hline
\end{tabular}


Relaciones artísticas entre la Haggadah de Sarajevo y la cerca exterior del coro...

(Continuación)

\begin{tabular}{|c|c|c|}
\hline TOLEDO & SARAJEVO & SALISBURY \\
\hline $\begin{array}{l}\text { La teofania de Mambré } \\
\text { (Gén. XVIII, 1-5; XIX, 1). }\end{array}$ & & $\begin{array}{l}\text { Teofanía de Mambré } \\
\text { (Gén., XVIII, 1-15; XIX, 1). }\end{array}$ \\
\hline \multirow[t]{3}{*}{$\begin{array}{l}\text { Historia de Lot: Destruc- } \\
\text { ción de Sodoma y Go- } \\
\text { morra (Gén., XIX, 27-29). }\end{array}$} & $\begin{array}{l}\text { Historia de Lot: Destruc- } \\
\text { ción de Sodoma y Go- } \\
\text { morra (Gén., XIX, 27-29). }\end{array}$ & $\begin{array}{l}\text { Historia de Lot: destruc- } \\
\text { ción de Sodoma y Go- } \\
\text { morra (Gén., XIX, 27-29). }\end{array}$ \\
\hline & $\begin{array}{l}\text { La mujer de Lot conver- } \\
\text { tida en estatua de sal } \\
\text { (Gén. XIX, 26). }\end{array}$ & $\begin{array}{l}\text { La mujer de Lot conver- } \\
\text { tida en estatua de sal } \\
\text { (Gén., XIX, 26). }\end{array}$ \\
\hline & $\begin{array}{l}\text { Lot, su mujer e hijas de- } \\
\text { jan Sodoma (Gén., XIX, } \\
\text { 30). }\end{array}$ & $\begin{array}{l}\text { Lot, su mujer e hijas de- } \\
\text { jan Sodoma (Gén., XIX, } \\
30 \text { ). }\end{array}$ \\
\hline $\begin{array}{l}\text { Historia de Abraham: Sa- } \\
\text { crificio de Isaac (Gén., } \\
\text { XXII, 1-2). } \\
\text { Sacrificio del carnero } \\
\text { (Gén., XXII, 13). }\end{array}$ & $\begin{array}{l}\text { Historia de Abraham: Sa- } \\
\text { crificio de Isaac (Gén., } \\
\text { XXII, 1-2). } \\
\text { Los sirvientes de Abra- } \\
\text { ham Ilevan el asno (Gén., } \\
\text { XXII, 3). } \\
\text { Este con el cuchillo e } \\
\text { Isaac con el haz de leña } \\
\text { (Gén., XXII, 6). } \\
\text { El carnero enredado en } \\
\text { un matorral (Gén., XXII, } \\
\text { 13). } \\
\text { La Mano Divina detiene } \\
\text { a Abraham (Gén., XXII, } \\
\text { 11). } \\
\text { Isaac tendido sobre el al- } \\
\text { tar para ser sacrificado } \\
\text { (Gén., XXII, 1-2). }\end{array}$ & $\begin{array}{l}\text { Abraham es detenido por } \\
\text { el ángel al sacrificar a su } \\
\text { hijo (Gén., } X X, 11 \text { ). }\end{array}$ \\
\hline \multicolumn{3}{|c|}{ IV. Historia de Isaac y de Jacob } \\
\hline & $\begin{array}{l}\text { Isaac encuentra a Rebe- } \\
\text { ca (Gén., XXV, 20). }\end{array}$ & \\
\hline & $\begin{array}{l}\text { Nacimiento de los ge- } \\
\text { melos de Raquel (Gén., } \\
X X V, 22) \text {. }\end{array}$ & \\
\hline & $\begin{array}{l}\text { Esaú, cazador (Gén., } \\
\text { XXV, 27). }\end{array}$ & \\
\hline & Isaac estudia la Ley. & \\
\hline
\end{tabular}


(Continuación)

\begin{tabular}{|c|c|c|}
\hline TOLEDO & SARAJEVO & SALISBURY \\
\hline \multicolumn{3}{|l|}{$\begin{array}{l}\text { Rebeca habla con Jacob } \\
\text { (Gén. XXVII, 1-14). }\end{array}$} \\
\hline $\begin{array}{l}\text { Jacob palpa a Jacob } \\
\text { (Gén. XXVII, 15-23). }\end{array}$ & $\begin{array}{l}\text { Isaac palpa a Jacob en } \\
\text { presencia de Raquel } \\
\text { (Gén., XXVII, 22-23). }\end{array}$ & $\begin{array}{l}\text { Isaac palpa a Jacob en } \\
\text { presencia de Raquel } \\
\text { (Gén., XXVII, 24-29). }\end{array}$ \\
\hline \multirow[t]{3}{*}{$\begin{array}{l}\text { Esaú ante Isaac para re- } \\
\text { cibir su bendición (Gén., } \\
\text { XXVII, 24-40). }\end{array}$} & $\begin{array}{l}\text { Esaú, que ha cazado una } \\
\text { liebre con una ballesta, } \\
\text { va a recibir la bendición } \\
\text { de Isaac, que extiende } \\
\text { sus brazos dolorosamen- } \\
\text { te (Gén., 24-40). }\end{array}$ & $\begin{array}{l}\text { Esaú ante Isaac para re- } \\
\text { cibir su bendición (Gén., } \\
\text { XXVII, 24-40). }\end{array}$ \\
\hline & & $\begin{array}{l}\text { Jacob envía a Jacob a } \\
\text { Paddan-Aram (Gén., } \\
\text { XXVIII, 1-5). }\end{array}$ \\
\hline & $\begin{array}{l}\text { Jacob dormido y Bétel } \\
\text { (Gén., XXVIII, 11). }\end{array}$ & $\begin{array}{l}\text { Jacob toma una piedra } \\
\text { para cabezal (Gén., } \\
\text { XXVIII, } 11 \text { ). }\end{array}$ \\
\hline \multirow[t]{3}{*}{$\begin{array}{l}\text { Sueño de Jacob (Gén., } \\
\text { XXVIII, 10-17). }\end{array}$} & $\begin{array}{l}\text { Jacob dormido y visión } \\
\text { de la escala celeste } \\
\text { (Gén. XXVIII, 12-15). }\end{array}$ & $\begin{array}{l}\text { Visión de la escala celes- } \\
\text { te con ángeles (Gén., } \\
\text { XXVIII, 12-15). }\end{array}$ \\
\hline & $\begin{array}{l}\text { Jacob vertiendo aceite } \\
\text { sobre el altar en acción } \\
\text { de gracias (Gén., XXVIII, } \\
\text { 18). }\end{array}$ & \\
\hline & & $\begin{array}{l}\text { Raquel, Jacob y Labán } \\
\text { (Gén., XXIX, 9-14). }\end{array}$ \\
\hline \multirow[t]{3}{*}{$\begin{array}{l}\text { Jacob lucha contra Dios } \\
\text { en figura de ángel (Gén., } \\
\text { XXXII, 23-25). }\end{array}$} & & $\begin{array}{l}\text { Jacob lucha contra Dios } \\
\text { en figura de ángel (Gén., } \\
\text { XXXII, 23-25). }\end{array}$ \\
\hline & & $\begin{array}{l}\text { El «ángel» disloca el fé- } \\
\text { mur a Jacob (Gén., XXXII, } \\
\text { 26), }\end{array}$ \\
\hline & & $\begin{array}{l}\text { Encuentro de Esaú y Ja- } \\
\text { cob (Gén., XXXIII, 1-11). }\end{array}$ \\
\hline $\begin{array}{l}\text { Jacob y los ídolos (Gén., } \\
X X X V, 1-8 \text { ). }\end{array}$ & & \\
\hline
\end{tabular}


Relaciones artísticas entre la Haggadah de Sarajevo y la cerca exterior del coro...

(Continuación)

\begin{tabular}{|c|c|c|}
\hline TOLEDO & SARAJEVO & SALISBURY \\
\hline \multicolumn{3}{|c|}{ IV. Historia de José } \\
\hline & & $\begin{array}{l}\text { Sueños de José (Gén., } \\
\text { XXXVII, 5-9). }\end{array}$ \\
\hline & $\begin{array}{l}\text { José cuenta los sueños a } \\
\text { su padre y hermanos; és- } \\
\text { tos se mofan de él (Gén., } \\
\text { XXXVII, 10-11). }\end{array}$ & $\begin{array}{l}\text { José relata su sueños } \\
\text { (Gén., XXXVII, 10-11). }\end{array}$ \\
\hline & $\begin{array}{l}\text { Los hermanos de José lo } \\
\text { arrojan en un pozo y ma- } \\
\text { tan un cabrito para man- } \\
\text { char con sangre su túni- } \\
\text { ca (Gén., XXXVII, 20-24). }\end{array}$ & $\begin{array}{l}\text { José es arrojado en un } \\
\text { pozo por sus hermanos } \\
\text { (y meten la túnica man- } \\
\text { chada de sangre de un } \\
\text { cabrito (Gén., XXXVII, 20- } \\
\text { 24). }\end{array}$ \\
\hline $\begin{array}{l}\text { Venta de José a los is- } \\
\text { maelitas (Gén., XXXVII, } \\
27-28 \text { ). }\end{array}$ & $\begin{array}{l}\text { Venta de José a los is- } \\
\text { maelitas (Gén., XXXVII, } \\
27-28 \text { ). }\end{array}$ & $\begin{array}{l}\text { Venta de José a los is- } \\
\text { maelitas (Gén., XXXVII, } \\
27-28 \text { ). }\end{array}$ \\
\hline \multirow[t]{7}{*}{$\begin{array}{l}\text { Los hermanos de José } \\
\text { entregan la túnica de } \\
\text { éste a Jacobo (Gén., } \\
\text { XXXVII, 31-35). }\end{array}$} & & $\begin{array}{l}\text { Los hermanos de José } \\
\text { entregan la túnica de } \\
\text { éste a Jacobo (Gén., } \\
\text { XXXVII, 31-35). }\end{array}$ \\
\hline & & Faraón recibe a José. \\
\hline & $\begin{array}{l}\text { José es tentado por la } \\
\text { mujer de Putifar (Gén., } \\
\text { XXXIX, 7-12). }\end{array}$ & $\begin{array}{l}\text { José es tentado por la } \\
\text { mujer de Putifar (Gén., } \\
\text { XXXIX, 7-12). }\end{array}$ \\
\hline & & $\begin{array}{l}\text { José es acusado ante Fa- } \\
\text { raón (Gén., XXXIX, 16- } \\
\text { 19). }\end{array}$ \\
\hline & $\begin{array}{l}\text { José es encarcelado } \\
\text { (Gén., XXXIX, 20). }\end{array}$ & $\begin{array}{l}\text { José es encarcelado } \\
\text { (Gén., XXXIX, 20). }\end{array}$ \\
\hline & $\begin{array}{l}\text { José interpreta los sue- } \\
\text { ños de! jefe de los es- } \\
\text { canciadores y del de pa- } \\
\text { naderos (Gén., XL, 1-19). }\end{array}$ & $\begin{array}{l}\text { José interpreta los sue- } \\
\text { ños del jefe de escancia- } \\
\text { dores y del de panaderos } \\
\text { (Gén., XL, 1-19). }\end{array}$ \\
\hline & $\begin{array}{l}\text { José se convierte en } \\
\text { hombre de confianza y } \\
\text { lleva las llaves de la pri- } \\
\text { sión (Gén., XXXIX, } 21 \text {. } \\
\text { 23). }\end{array}$ & \\
\hline
\end{tabular}


(Continuación)

\begin{tabular}{|c|c|c|}
\hline TOLEDO & SARAJEVO & SALISBURY \\
\hline & & $\begin{array}{l}\text { El jefe de panaderos es } \\
\text { colgado y el de escancia- } \\
\text { dores restituido en su } \\
\text { cargo (Gén., XL, 20-23). }\end{array}$ \\
\hline & $\begin{array}{l}\text { Sueños de Faraón (Gén., } \\
\text { XLI, 1-7). }\end{array}$ & $\begin{array}{l}\text { Sueños de Faraón (Gén., } \\
\text { XLI, 1-7). }\end{array}$ \\
\hline & & $\begin{array}{l}\text { Faraón con el mago y el } \\
\text { panadero (Gén., XLI, 8- } \\
\text { 13). }\end{array}$ \\
\hline & $\begin{array}{l}\text { José interpreta los sue- } \\
\text { ños de Faraón en pre- } \\
\text { sencia de sus servidores } \\
\text { (Gén., XLI, 14-36). }\end{array}$ & $\begin{array}{l}\text { José interpreta los sue- } \\
\text { ños de Faraón en pre- } \\
\text { sencia de sus servidores } \\
\text { (Gén., XLI, 14-36). }\end{array}$ \\
\hline & $\begin{array}{l}\text { José, primer ministro, su- } \\
\text { pervisando el trigo (Gén., } \\
\text { XLI, 37-49). }\end{array}$ & $\begin{array}{l}\text { José, primer ministro, su- } \\
\text { pervisando el trigo (Gén., } \\
\text { XLI, 37-49). }\end{array}$ \\
\hline & $\begin{array}{l}\text { Súplica de los hermanos } \\
\text { de José a éste (Gén., } \\
\text { XLII, 6-7). }\end{array}$ & $\begin{array}{l}\text { Súplica de los hermanos } \\
\text { de José a éste (Gén., } \\
\text { XLII, 6-7). }\end{array}$ \\
\hline & $\begin{array}{l}\text { Los hermanos de José } \\
\text { llenan los sacos (Gén., } \\
\text { XLII, 25-26). }\end{array}$ & $\begin{array}{l}\text { Los hermanos de José } \\
\text { llenan los sacos (Gén., } \\
\text { XLII, 25-26) }\end{array}$ \\
\hline & $\begin{array}{l}\text { José invita a sus herma- } \\
\text { nos a su mesa (Gén., } \\
\text { XLIII, } 25 ; 31-34) \text {. }\end{array}$ & \\
\hline & & $\begin{array}{l}\text { Benjamín es presentado } \\
\text { a José (Gén., XLIII, } 29 \text { - } \\
\text { 30). }\end{array}$ \\
\hline & & $\begin{array}{l}\text { Es metida la copa de } \\
\text { José en el saco de Ben- } \\
\text { jamín por orden de aquél } \\
\text { (Gén., XLIV, 1-2). }\end{array}$ \\
\hline & $\begin{array}{l}\text { Benjamín acusado de ro- } \\
\text { bar una copa de José } \\
\text { (Gén., XLIV, 4-11). }\end{array}$ & $\begin{array}{l}\text { Benjamín acusado de ro- } \\
\text { bar una copa de José } \\
\text { (Gén., XLIV, 4-11). }\end{array}$ \\
\hline & $\begin{array}{l}\text { Los hermanos de José se } \\
\text { rasgan las vestiduras } \\
\text { (Gén., XLIV, 13). }\end{array}$ & \\
\hline
\end{tabular}


Relaciones artisticas entre la Haggadah de Sarajevo y la cerca exterior del coro...

(Continuación)

\begin{tabular}{|c|c|c|}
\hline TOLEDO & SARAJEVO & SALISBURY \\
\hline & $\begin{array}{l}\text { Judá intercede por sus } \\
\text { hermanos (Gén., XLIV, } \\
\text { 18-34). }\end{array}$ & \\
\hline \multirow[t]{8}{*}{$\begin{array}{l}\text { José se hace reconocer } \\
\text { por sus hermanos (Gén., } \\
\text { XLV } 1-8 \text { ). }\end{array}$} & $\begin{array}{l}\text { José se hace reconocer } \\
\text { por sus hermanos (Gén., } \\
\text { XLV, 1-8). }\end{array}$ & $\begin{array}{l}\text { José se hace reconocer } \\
\text { por sus hermanos (Gén., } \\
\text { XLV, 1-8). }\end{array}$ \\
\hline & $\begin{array}{l}\text { José abraza a Benjamín } \\
\text { (Gén., XLV, 14). }\end{array}$ & $\begin{array}{l}\text { José abraza a Benjamín } \\
\text { (Gén., XLV, 14). }\end{array}$ \\
\hline & $\begin{array}{l}\text { Jacob recibe a sus hijos } \\
\text { de regreso de Egipto; el } \\
\text { pequeño Benjamín, mon- } \\
\text { tado en una carreta } \\
\text { (Gén., XLV, 21-27). }\end{array}$ & \\
\hline & $\begin{array}{l}\text { Jacob y su familia salen } \\
\text { para Egipto (Gén., XLVI, } \\
1-7 \text { ). }\end{array}$ & $\begin{array}{l}\text { Jacob y su familia salen } \\
\text { para Egipto (Gén., XLVI, } \\
1-7 \text { ). }\end{array}$ \\
\hline & & $\begin{array}{l}\text { José abraza a su padre } \\
\text { (Gén., XLVI, 29). }\end{array}$ \\
\hline & $\begin{array}{l}\text { El ataúd de Jacob es lle- } \\
\text { vado a Canaán por sus } \\
\text { doce hijos y dos nietos } \\
\text { ataviados de luto (Gén., } \\
\text { XLIX, 29; L, 1-14). }\end{array}$ & \\
\hline & $\begin{array}{l}\text { José y sus hermanos } \\
\text { ante Faraón. }\end{array}$ & \\
\hline & $\begin{array}{l}\text { Muerte de José; este co- } \\
\text { locado sobre un ataúd } \\
\text { "en Egipto" (Gén., L, 24- } \\
\text { 26). }\end{array}$ & \\
\hline \multicolumn{3}{|c|}{ Exodo } \\
\hline & $\begin{array}{l}\text { Encuentro de Moisés } \\
\text { (Ex., II, 1-10). }\end{array}$ & \\
\hline & $\begin{array}{l}\text { Moisés, pastor, ve la zar- } \\
\text { za ardiente (Ex., III, 1-6). }\end{array}$ & $\begin{array}{l}\text { Moisés y la zarza ardien- } \\
\text { te (Ex., III, 1-6). }\end{array}$ \\
\hline & $\begin{array}{l}\text { Moisés y Aarón en la cor- } \\
\text { te de Faraón; su vara-ser- } \\
\text { piente traga a las otras } \\
\text { (Ex., VII, 8-13). }\end{array}$ & \\
\hline
\end{tabular}


(Continuación)

\begin{tabular}{|c|c|c|}
\hline TOLEDO & SARAJEVO & SALISBURY \\
\hline \multicolumn{3}{|c|}{ II. Las plagas de Egipto. La Pascua } \\
\hline $\begin{array}{l}11^{a} \text { plaga: el agua se con- } \\
\text { vierte en sangre (Ex., VII, } \\
14-20) \text {. }\end{array}$ & $\begin{array}{l}1 .{ }^{a} \text { plaga: el agua se con- } \\
\text { vierte en sangre; los } \\
\text { egipcios cavan en vano } \\
\text { para obtener agua (Ex., } \\
\text { VII, 14-20). }\end{array}$ & \\
\hline \multirow[t]{2}{*}{$\begin{array}{l}\text { 2. }{ }^{a} \text { plaga: las ranas (Ex., } \\
\text { VII, 25-29; VIII, 1-2). }\end{array}$} & $\begin{array}{l}2{ }^{a} \text { plaga: las ranas co- } \\
\text { rriendo por dentro de una } \\
\text { chimenea, el horno, etc. } \\
\text { (Ex., VII, 25-29; VIII, 1-2). }\end{array}$ & \\
\hline & $\begin{array}{l}\text { 3. a plaga: los mosquitos } \\
\text { (Ex., VIII, 12-15). }\end{array}$ & \\
\hline $\begin{array}{l}\text { 4. plaga: los tábanos } \\
(\text { Ex., VIII, 16-20). }\end{array}$ & $\begin{array}{l}4 .^{a} \text { plaga: los tábanos, } \\
\text { bajo formas salvajes: es- } \\
\text { corpiones, cocodrilos y } \\
\text { una serpiente voladora } \\
\text { (Ex., VIII, 16-20). }\end{array}$ & \\
\hline \multirow[t]{2}{*}{$\begin{array}{l}\text { 5. plaga: muerte del ga- } \\
\text { nado (Ex., IX, 1-6). }\end{array}$} & $\begin{array}{l}\text { 5. plaga: muerte del ga- } \\
\text { nado (Ex., IX, 1-6). }\end{array}$ & \\
\hline & $\begin{array}{l}\text { 6. }{ }^{\text {a }} \text { laga: las úlceras, } \\
\text { ante el desconcierto de } \\
\text { los adivinos (Ex., IX, 8- } \\
\text { 12). }\end{array}$ & \\
\hline $\begin{array}{l}\text { 7. plaga: la granizada } \\
(\text { Ex., IX, 22-25) }\end{array}$ & $\begin{array}{l}7 .^{a} \text { plaga: la granizada } \\
(\text { Ex., }(X, 22-25) \text {. }\end{array}$ & \\
\hline \multirow[t]{2}{*}{$\begin{array}{l}\text { 8. } .^{A} \text { plaga: las langostas } \\
(E x ., X, 14-20)\end{array}$} & $\begin{array}{l}8 .^{a} \text { plaga: las langostas } \\
(E x ., X, 14-20) .\end{array}$ & \\
\hline & $\begin{array}{l}9 .^{a} \text { plaga: las tinieblas } \\
(\text { Ex., } X, 21-29) \text {. }\end{array}$ & \\
\hline \multicolumn{3}{|l|}{$\begin{array}{l}\text { Institución de la Pascua } \\
\text { (Ex., XII, 1-6; 8-11). }\end{array}$} \\
\hline $\begin{array}{l}\text { Identificación de las } \\
\text { puertas de los hebreos } \\
\text { (Ex., XII, 7). }\end{array}$ & & \\
\hline
\end{tabular}


Relaciones antísticas entre la Haggadah de Sarajevo y la cerca exterior del coro...

(Continuación)

\begin{tabular}{|c|c|c|}
\hline TOLEDO & SARAJEVO & SALISBURY \\
\hline \multirow[t]{2}{*}{$\begin{array}{l}\text { 10. }{ }^{a} \text { plaga: muerte de los } \\
\text { primogénitos de los egip- } \\
\text { cios (Ex., XII, 12-13). }\end{array}$} & $\begin{array}{l}10 \text { a plaga: muerte de los } \text { primogénitos de los egip- } \\
\text { cios, atacados por ratas } \\
\text { y vampiros (Ex., XII, 12- } \\
\text { 13). }\end{array}$ & \\
\hline & $\begin{array}{l}\text { Faraón manda salir a } \\
\text { Moisés, Aarón y su pue- } \\
\text { blo (Ex., XIII, 31-34). }\end{array}$ & \\
\hline \multicolumn{3}{|c|}{ III. Paso del Mar Rojo } \\
\hline $\begin{array}{l}\text { Paso del Mar Rojo (Ex., } \\
\text { XIV, 19-22). }\end{array}$ & $\begin{array}{l}\text { Paso del Mar Rojo; los hi- } \\
\text { jos de Israel con sus en- } \\
\text { seres a hombros (Ex., } \\
\text { XIV, 19-22). }\end{array}$ & $\begin{array}{l}\text { Paso del Mar Rojo (Ex., } \\
\text { XIV, 19-22). }\end{array}$ \\
\hline \multirow[t]{3}{*}{$\begin{array}{l}\text { Persecución y muerte de } \\
\text { los egipcios (Ex., XIV, 23- } \\
28 \text { ). }\end{array}$} & $\begin{array}{l}\text { Persecución y muerte de } \\
\text { los egipcios (Ex., XIV, 23- } \\
\text { 28). }\end{array}$ & $\begin{array}{l}\text { Persecución y muerte de } \\
\text { los egipcios (Ex., XIV, 23- } \\
\text { 28). }\end{array}$ \\
\hline & $\begin{array}{l}\text { El Faraón, en concordan- } \\
\text { cia con la tradición judía, } \\
\text { sobrevive. }\end{array}$ & \\
\hline & $\begin{array}{l}\text { Miriam dirige a las hijas } \\
\text { de Israel en la danza de } \\
\text { acción de gracias (Ex., } \\
X V, 20-21 \text { ). }\end{array}$ & \\
\hline EI Maná (Ex., XVI, 9-16). & $\begin{array}{l}\text { El Maná. Aarón conserva } \\
\text { un poco en una olla; los } \\
\text { israelitas levantan las pal- } \\
\text { mas y pozos de Elim. }\end{array}$ & \\
\hline $\begin{array}{l}\text { Moisés saca agua de la } \\
\text { roca del monte Horeb } \\
\text { (Ex., XVII, 1-6). }\end{array}$ & & $\begin{array}{l}\text { Moisés saca agua de la } \\
\text { roca del monte Horeb } \\
\text { (Ex., XVII, 1-6). }\end{array}$ \\
\hline \multicolumn{3}{|l|}{$\begin{array}{l}\text { Batalla contra Amalec } \\
(\text { Ex., XVII, 11-15). }\end{array}$} \\
\hline & & $\begin{array}{l}\text { El Señor entrega a Moi- } \\
\text { sés las Tablas de la Ley } \\
\text { (Ex., XXXI, 18). }\end{array}$ \\
\hline \multicolumn{3}{|c|}{ IV. La Alianza en el Sinai } \\
\hline $\begin{array}{l}\text { La Teofanía (Ex., XIX, 16- } \\
\text { 25). }\end{array}$ & & \\
\hline
\end{tabular}


(Continuación)

\begin{tabular}{|c|c|c|}
\hline TOLEDO & SARAJEVO & SALISBURY \\
\hline \multicolumn{3}{|l|}{$\begin{array}{l}\text { El becerro de oro (Ex., } \\
\text { XXXII, } 1-5 ; 15-24) \text {. }\end{array}$} \\
\hline & $\begin{array}{l}\text { Moisés en el Sinaí porta } \\
\text { los diez Mandamientos, } \\
\text { mientras la Voz de Dios } \\
\text { suena en el cuerno de un } \\
\text { carnero. Josué y el pue- } \\
\text { blo junto al monte (Ex., } \\
\text { XXXII, 11-16) }\end{array}$ & \\
\hline \multicolumn{3}{|l|}{$\begin{array}{l}\text { Moisés hace arrojar el } \\
\text { becerro triturado en un } \\
\text { recipiente (EX., XXXII, } \\
\text { 20). }\end{array}$} \\
\hline \multicolumn{3}{|l|}{$\begin{array}{l}\text { Moisés ordena matar a } \\
\text { los hebreos idólatras } \\
\text { (Ex., XXXII, 25-28). }\end{array}$} \\
\hline \multicolumn{3}{|l|}{$\begin{array}{l}\text { Renovación de la Alianza. } \\
\text { Nuevas Tablas de la Ley } \\
\text { (Ex., XXXIV, 1-5). }\end{array}$} \\
\hline \multirow[t]{5}{*}{$\begin{array}{l}\text { Cántico de Moisés (Dt. } \\
\text { XXXII, 1-43). }\end{array}$} & $\begin{array}{l}\text { Cántico de Moisés (Dt. } \\
\text { XXXII, 1.43). }\end{array}$ & \\
\hline & $\begin{array}{l}\text { Moisés coloca sus ma- } \\
\text { nos sobre la frente de Jo- } \\
\text { sué frente al monte } \\
\text { Nebo, siendo designado } \\
\text { sucesor suyo, en presen- } \\
\text { cia de los representantes } \\
\text { de las doce tribus. }\end{array}$ & \\
\hline & $\begin{array}{l}\text { El Tabernáculo mostran- } \\
\text { do las alas de un que- } \\
\text { rubín y cerrando los diez } \\
\text { Mandamientos. }\end{array}$ & \\
\hline & $\begin{array}{l}\text { Distribución de un haro- } \\
\text { seth y del pan ázimo. }\end{array}$ & \\
\hline & $\begin{array}{l}\text { Interior de la sinagoga } \\
\text { con los rollos de la Ley } \\
\text { dentro del relicario de la } \\
\text { Torá y la comunidad sa- } \\
\text { liendo tras finalizar el ser- } \\
\text { vicio religioso. }\end{array}$ & \\
\hline
\end{tabular}

